\title{
Pulmonary Function Assessment Method with Type II Non-heart Beating Donors in Spain is Valid
}

\author{
${ }^{1}$ Department of Thoracic Surgery, Hospital 12 de Octubre, Madrid, Spain \\ ${ }^{2}$ Department of Pathology, Hospital 12 de Octubre, Madrid, Spain \\ ${ }^{3}$ Department of Thoracic Surgery, Hospital 12 de Octubre, Madrid, Spain \\ ${ }^{4}$ Department of Anesthesiology, Hospital 12 de Octubre, Madrid, Spain \\ ${ }^{5}$ Department of Pulmonology, Hospital 12 de Octubre, Madrid, Spain
}

Jose Carlos Meneses ${ }^{1 *}$, Pablo Gámez ${ }^{1}$, Andrea Mariscal ${ }^{1}$, Ana Belen Enguita ${ }^{2}$, Regulo Ávila ${ }^{3}$, Adolfo García ${ }^{4}$ and Rodrigo Alonso ${ }^{5}$

\begin{abstract}
Lung transplantation unit from Hospital 12 de Octubre began its work in October 2008. In the last five years, 80 lung transplants have been performed with a hospital mortality rate of $6.5 \%$ and a five years survival of $79.7 \%$. As a result of the need of obtaining a greater number of donors, and encouraged by the outpatient non heart beating donors program within our hospital, we considered the possibility of assessing these donors lung grafts. We have followed the methodology designed and set off with good results by other hospitals in the area of Madrid. Nevertheless some changes have been included such as Bithermical multiorgan preservation, where abdominal organs are preserved in normothermia and thoracic ones in hypothermia. However, this methodology has not been scientifically proven. We have reproduced in a laboratory lung function assessment manoeuvres of pulmonary grafts from non heart beating donors. Then we have compared the correlation with the lung function assessment before cardiac arrest, applying the procedure on 40 pigs. Outcomes are promising.
\end{abstract}

\section{Introduction}

First solid organ transplantations were performed using graft from donors after cardiac arrest. In 1933, Voronoy [1] performed the very first kidney transplantation in Ukraine. In 1963, Hardy et al. [2] performed in the USA the first lung transplantation by means of a donor after severe heart attack. Later on, most donations came from brain dead donor patients, given a greater donor control within hospitals. More specifically since 1971 [3] when the first brain dead donor legal entity was established in Finland.

As patients needing a lung transplantation survival rate improved, waiting lists have gone up, and the number of brain dead donors has decreased (due to lower death rate trends for RTAs and CVAs [4], and an improvement on brain damage diagnosis and treatment). Therefore different strategies to satisfy the increasing demand were established. Among these strategies, we mention the acceptance of marginal donors, the assessment of cardiac arrest dead donors [5], and using of ex-vivo in order to optimize lungs considered unsuitable at first [6].

Love performed the first successful lung transplant using graft from a cardiac arrest patient in 1995, in Winsconsin. First NonHeart-Beating Donors (NHBD) protocol was designed at Pittsburgh University in 1996 [7]. First lung transplant from Non Heart beating Lung Donor (NHBLD) with graft preservation using ex-vivo system, was performed by Steen in 2001 [8,9]. A year later, in 2002, Hospital Puerta del Hierro Thoracic Surgeons (Madrid) started implanting the first lungs (preserved in hypothermia at the Hospital Clinico San Carlos) from uncontrolled non heart beating donors with excellent outcomes [10]. First lung transplant from a multiple organ non heart beating type II donor was accomplished at the Hospital 12 de Octubre, in Madrid. In this particular case abdominal organs were preserved using normothermia, with extracorporeal blood flow from the donor, while thoracic organs were preserved using hypothermia, with a cold Perfadex $^{\circledR}$ continuous flow. This is known as Bithermal Preservation [11].

Although NHBLD is far from perfect, it shows positive features. Lung damage produced by brain death is widely known, lung oedema not only as a consequence of vascular endothelium rupture but also due to inflammatory response deregulation [12]. NHBLD are rarely exposed to secondary damage caused by brain death [13], therefore this graft can be considered suitable to be implanted.

The scientific basis of cardiac arrest lung donor's viability lays on the fact that after death, the lung is the only solid organ not needing vascular perfusion for cell breathing, as it is a passive process. Some studies prove that epithelial lung cells can be grown from cadaver samples [14]. On the other hand, obtaining a gas exchange is possible up to two hours after cardiac arrest, without need of lung circulation, especially if oxygen has been blown into alveoli [15]. This time frame can be increased up to 4 hours after cadaver heparinization and up to $12-24$ hours if lungs are cooled down $\left(15\right.$ to $\left.20^{\circ} \mathrm{C}\right)$ [16]. Even though other countries started considering intra-hospital or controlled donors earlier, Spain was pioneer at considering outpatient donors. We are dealing with outpatients and a lack of peripheral perfusion, therefore lung function assessment method used with this type of donors cannot be the same as the one used with brain dead donors. After a mediam sternotomy, pericardium opening and a pulmonary artery cannulation, a solution of cold Perfadex ${ }^{\circledR}$ is delivered in order to clean lung flow from pool blood and thrombus. Later on, donor's blood previously drawn is also used. The effluent in the left atrium from this blood goes through gas analysis, as lungs are kept mechanically ventilated.

*Corresponding author: Jose Carlos Meneses, Department of Thoracic Surgery, Hospital 12 de Octubre, Madrid, Spain, Tel: +34639011990; E-mail: jcmenesesp@gmail.com

Received October 01, 2013; Accepted November 21, 2013; Published November 23, 2013

Citation: Meneses JC, Gámez P, Mariscal A, Enguita AB, Ávila R, et al. (2013) Pulmonary Function Assessment Method with Type II Non-heart Beating Donors in Spain is Valid. J Transplant Technol Res 3: 124. doi:10.4172/2161-0991.1000124

Copyright: (c) 2013 Meneses JC, et al. This is an open-access article distributed under the terms of the Creative Commons Attribution License, which permits unrestricted use, distribution, and reproduction in any medium, provided the original author and source are credited. 
However, this procedure has not been scientifically proven. Neither is exsanguinated donors being assessed. Based on the theory that lungs do not need blood for cell oxygenation they should be potential lung donors, since this process takes place passively, by means of alveolar space oxygen diffusion.

\section{Objectives}

We have decided to experimentally recreate, in an animal model, the assessment of pulmonary technique in uncontrolled non heart beating donor to demonstrate its soundness and establish the necessary modifications. We also aim to know whether the deceased subject due to a secondary non heart beating caused by exsanguination is valid as lung donor. Finally, we have tried to establish if carrying out the assessment of lung function with fluids others than autologous blood is possible, given the occasional difficulties when it comes to obtaining the needed amount to perform this method.

\section{Material and Methods}

With the aim of reproducing functional assessment maneuvers of lung graft from cardiac arrest donors in a laboratory, and the aim of comparing its correlation to lung functional assessment before cardiac arrest, the procedure was carried out on 40 hybrid pigs (Large White and Landrance) 4 to 6 months old, Healthy and with a weight of 30 to 35 kilograms.

Prior to surgery, the animal was kept on an empty stomach for at least 24 hours. Ketamine $(20 \mathrm{mg} / \mathrm{Kg} \mathrm{im})$, Xylazine $(2 \mathrm{mg} / \mathrm{Kg} \mathrm{im})$ and Atropine $(0.5 \mathrm{cc} \mathrm{im})$ were used for sedation. Propofol $1 \%$ was used for induction and anesthetic maintenance $(1.5 \mathrm{mg} / \mathrm{Kg} \mathrm{IV}$ in the induction and later on in perfusion $10 \mathrm{mg} / \mathrm{Kg} / \mathrm{h})$. Rocuronium $(0.5 \mathrm{mg} / \mathrm{Kg} / \mathrm{h})$ and Fentanyl were also used. The pig was kept on Invasive Mechanical Ventilation with endotracheal intubation with a number 6 simple tube with balloon, keeping a $10-15 \mathrm{mk} / \mathrm{Kg}$ tidal volume, with a 16 breaths/ minute rate, and fraction of inspired oxygen $\left(\mathrm{FiO}_{2}\right)>100 \%$ and $5 \mathrm{~cm}$ G2O PEEP. The next step was haemodynamic monitoring by means of EKG (3 electrodes on the chest) and blood pressure measurement, oxygen saturation and temperature. Finally heparinization, Sodium Heparin IV 3 mg/KG

The pigs underwent median sternotomy and then a first lung function assessment using left atrium $\left(\mathrm{pO}_{2} \mathrm{Al}\right) \mathrm{ABG}$ in peripheral blood $\left(\mathrm{pO}_{2} \mathrm{SP}\right)$ and Aorta $\left(\mathrm{pO}_{8} \mathrm{Ao}\right) .300 \mathrm{cc}$ of the animal blood were drawn by means of a right ventricle puncture. After that, the mediastinal structures were dissected to cannulate the lung artery and section the left atrium appendage with a "tobacco-pouch" suture technique. The sample was divided into two groups, in order to compare lung function assessment in exsanguinated donors and the one in sudden death donors. In this sense euthanasia was performed in 20 animals by forcing heart arrest with potassium chloride (group 1), and by means of superior vena cava section exsanguination in the other 20. After that, the superior vena cava was bound and the aortic root clamped. Then functional assessment was done after pulmonary artery instillation of $300 \mathrm{cc}\left(\mathrm{pO}_{2}\right.$ 300), $600\left(\mathrm{pO}_{2} 600\right), 900 \mathrm{cc}\left(\mathrm{pO}_{2} 900\right)$, and $1200 \mathrm{cc}\left(\mathrm{pO}_{2}\right.$ 1200) Perfadex ${ }^{\mathbb{R}} 4^{\circ} \mathrm{C}$, and subsequently, $300 \mathrm{cc}$ of the animal own blood $\left(\mathrm{pO}_{2} \mathrm{BLOOD}\right)$. Blood gas samples were produced from the left atrium at all times. In all samples, a $\mathrm{pO}_{2}$ with GemPremier3000 analyzer was established. Prior to the beginning of each individual, external quality controls suggested by the manufacturer were carried out, as well as internal quality ones that the machine automatically runs. All results were corrected according to the average temperature of the left atrium by means of tissue thermometer (Thermistor). Finally, data was analyzed by means of paired T-test in order to establish statistical differences between $\mathrm{pO}_{2}$ values before and after animal death, and also by means of Wilcoxon Test in order to establish statistical differences between $\mathrm{pO}_{2}$ in the left atrium after perfusing several $300 \mathrm{cc}$ preservation solution segments.

\section{Results}

A total of 36 out of 41 individuals were considered valid for the analysis. 4 animals were rejected ( 3 of them belonging to group 1 and only one to group 2), the reasons being: gas analyzer breakdown, cardiac arrest prior to procedure start, pulmonary vascular system thrombus and severe sternal adhesions that made mediastinal dissection impossible.

Comparisons between $\mathrm{pO}_{2} \mathrm{AI}$ values were carried out, since no significant differences between $\mathrm{pO}_{2} \mathrm{SP}$ and $\mathrm{pO}_{2}$ Ao values were noticed. In group 1, the $\mathrm{pO}_{2} \mathrm{AI}$ average was $437.5 \mathrm{mmHg}$ (DS: 66.77) and that of $\mathrm{pO}_{2} 300, \mathrm{pO}_{2} 600 \mathrm{cc}, \mathrm{pO}_{2} 900, \mathrm{pO}_{2} 1200 \mathrm{cc}$ y $\mathrm{pO}_{2}$ BLOOD was 337.81 $\mathrm{mmHg}, 446.13 \mathrm{mmHg}, 438.81 \mathrm{mmHg}, 538.0 \mathrm{mmHg}$ y $431.94 \mathrm{mmHg}$ respectively. In group 2, the $\mathrm{pO}_{2} \mathrm{AI}$ average was $438.37 \mathrm{mmHg}$ and the $\mathrm{pO}_{2} 300, \mathrm{pO}_{2} 600 \mathrm{cc}, \mathrm{pO}_{2} 900, \mathrm{pO}_{2} 1200 \mathrm{cc}$ y $\mathrm{pO}_{2}$ BLOOD was that of $443.80 \mathrm{mmHg}, 489.55 \mathrm{mmHg}, 552.6 \mathrm{mmHg}, 572.15 \mathrm{mmHg}$ y 418.65 $\mathrm{mmHg}$ respectively. Average temperatures taken at all times for both groups were $37.21 \pm 2.38^{\circ} \mathrm{C}$ in pre-arrest $\mathrm{AI}, 24.59 \pm 3.78^{\circ} \mathrm{C}, 21.53 \pm$ $2.98^{\circ} \mathrm{C}, 19.81 \pm 3.05^{\circ} \mathrm{C}$ and $18.59 \pm 3.31^{\circ} \mathrm{C}$ after $300 \mathrm{cc}, 600 \mathrm{cc}, 900 \mathrm{cc}$ y $1200 \mathrm{cc}$ Perfadex perfusion, and $24.68 \pm 2.59^{\circ} \mathrm{C}$ after $300 \mathrm{cc}$ blood perfusion.

The whole of the determinations value average is described on table1. By means of paired T-Test were no statistically significant differences where objectified between $\mathrm{pO}_{2}$ pre-arrest and $\mathrm{pO}_{2}$ postarrest in AI in group 2 (Table 2). According to this test, given a hypothesis where there were significant differences between $\mathrm{pO}_{2} \mathrm{AI}$ and $\mathrm{pO}_{2} \mathrm{BLOOD}$ in group 1 , a $\mathrm{p}=0.5183$. Therefore we can conclude that there are no statistically significant differences for these values in the group with CIK cardiac arrest.

After using Test- $\mathrm{T}$ with the hypothesis where there are significant differences between $\mathrm{pO}_{2} \mathrm{AI}$ and $\mathrm{pO}_{2} 300, \mathrm{pO}_{2} 600$ and $\mathrm{pO}_{2} 1200$ between both groups, unlike values came up. Only in the case of $\mathrm{pO}_{2} \mathrm{AI}$ and $\mathrm{pO}_{2}$ 600 statistic differences are ruled out, being $p=0.3876$ (Table 3 ).

\begin{tabular}{|c|c|c|c|c|c|c|c|c|c|}
\hline Variable & Mean & Std Dev & Minimum & 25th Pctl & 50th Pctl & 75th Pctl & Maximum & $\mathbf{N}$ & N Miss \\
\hline $\mathrm{pO}_{2} \mathrm{PRE}$ & 430.48 & 67.37 & 288.00 & 392.00 & 435.00 & 479.00 & 557.00 & 33 & 3 \\
\hline $\mathrm{pO}_{2} \mathrm{Ao}$ & 470.78 & 67.70 & 321.00 & 430.50 & 468.50 & 520.00 & 619.00 & 36 & 0 \\
\hline $\mathrm{pO}_{2} \mathrm{LA}$ & 437.97 & 63.55 & 307.00 & 385.00 & 435.00 & 498.00 & 580.00 & 35 & 1 \\
\hline $\mathrm{pO}_{2} 300$ & 396.69 & 182.39 & 33.00 & 354.00 & 402.50 & 531.50 & 760.00 & 36 & 0 \\
\hline $\mathrm{pO}_{2} 600$ & 470.25 & 148.00 & 96.00 & 394.00 & 456.50 & 556.00 & 760.00 & 36 & 0 \\
\hline $\mathrm{pO}_{2} 900$ & 502.03 & 137.14 & 41.00 & 450.50 & 510.50 & 558.00 & 760.00 & 36 & 0 \\
\hline $\mathrm{pO}_{2} 1200$ & 556.97 & 110.66 & 374.00 & 489.00 & 532.00 & 586.50 & 760.00 & 36 & 0 \\
\hline $\mathrm{pO}_{2}$ blood & 424.56 & 130.79 & 30.00 & 358.00 & 442.00 & 496.50 & 656.00 & 36 & 0 \\
\hline
\end{tabular}

Table 1: $\mathrm{pO}_{2}$ determination values. 
Wilcoxon Test was used when comparing $\mathrm{pO}_{2}$ values at different times. In this case, no statistically significant differences were found, with the exception of variable $\mathrm{pO}_{2} 900$, being $\mathrm{p}=0.0311$ (Table 4).

When studying the possibility of a link between the $\mathrm{pO}_{2} \mathrm{Al}$ outcomes and after perfusing different quantities of preserving solution Perfadex ${ }^{\circledR}$, it was put in objective terms that outcomes followed a polynomial model. However, it is difficult to obtain a mathematical formula which allows practical decision making. To end up, a histological study was carried out on organs after different perfusions with segmental lung resection in the left lower lobe. The emphysema degree, the presence of alveolar, Insterstitial and peribronchial infiltration and the existence or absence of blood vessels alterations and visceral pleura were all studied. After histological studies outcome analysis, a great amount of variability was found. Therefore no practical conclusions were achieved.

\section{Discussion}

A different type of non heart beating donor, non-existent in other countries, can be found in Spain, uncontrolled or type II donor. This article presents the current way of functionally assessing lungs from type II non heart beating donors. We have aimed to prove in a laboratory context that lungs, after cardiac arrest, effectively oxygenate fluids on pulmonary artery instillation, as described in the study. We have also aimed to prove that there are not statistical differences between measurement before and after cardiac arrest.

Based on our results, we can state that the assessment procedure of lung function from outpatient donors in Spain, using effluent gas analysis in AI after blood instillation (from the own subject), has a high correlation with oxygenation measurement before cardiac arrest. No statistically significant differences were found.

In order to increase pool donors in our country, the capacity of using organs from patients dead after exsanguination in multiple trauma (traffic accidents, blade weapons and firearms injuries, etc.) has sometimes been discussed More specifically, deaths caused by abdominal or pelvic trauma, but not pulmonary one. We are dealing with exsanguinated patients who can be potential lung donors, since lungs (contrary to any other organs) do not require blood perfusion in order to maintain tissue oxygenation. This is a passive process. It

\begin{tabular}{|c|c|c|c|}
\hline \multicolumn{4}{|c|}{ T-test } \\
\hline Differences & $\mathbf{N}$ & Valor T & Pr>/t/ \\
\hline $\mathrm{pO}_{2} \mathrm{LA}_{\mathrm{p}} \mathrm{pO}_{2}$ blood & 36 & 0.65 & 0.5183 \\
\hline
\end{tabular}

Table 2: T-Student for $\mathrm{pO}_{2}$ values in group 1 .

\begin{tabular}{|c|c|c|c|}
\hline \multicolumn{4}{|c|}{ T-test both groups } \\
\hline Differences & $\mathrm{DF}$ & $\mathrm{T}$ Valor & $\mathrm{Pr}>/ \mathrm{t} /$ \\
\hline $\mathrm{pO}_{2} \mathrm{LA}-\mathrm{pO}_{2} 300$ & 37 & 2.01 & 0.0515 \\
\hline $\mathrm{pO}_{2} \mathrm{Al}-\mathrm{pO}_{2} 600$ & 35 & -0.87 & 0.3876 \\
\hline $\mathrm{pO}_{2} \mathrm{Al}-\mathrm{pO}_{2} 900$ & 34 & -2.90 & 0.0065 \\
\hline $\mathrm{pO}_{2} \mathrm{Al}-\mathrm{pO}_{2} 1200$ & 34 & -5.88 & $<0001$ \\
\hline
\end{tabular}

Table 3: T-Student for different $\mathrm{pO}_{2}$ values in both groups.

Wilcoxon test, statical differences, groups 1 and 2

\begin{tabular}{|c|c|}
\hline $\mathrm{pO}_{2} \mathrm{LA}$ & 0.7301 \\
\hline $\mathrm{pO}_{2} 300$ & 0.1134 \\
\hline $\mathrm{pO}_{2} 600$ & 0.6246 \\
\hline $\mathrm{pO}_{2} 900$ & 0.0311 \\
\hline $\mathrm{pO}_{2} 1200$ & 0.4035 \\
\hline $\mathrm{pO}_{2}$ blood & 0.6359 \\
\hline
\end{tabular}

Table 4: Wilcoxon test for $\mathrm{pO}_{2}$ values in both groups. is proven in our study that after complete animal exsanguination, the lung can oxygenate fluids on pulmonary artery instillation. Even more, we have been able to conclude that lungs from exsanguinated animals not only keep their gas exchange capacity, but they also present more homogeneous outcomes. This study lays the scientific foundations for future protocols on non heart beating donors from deaths resulting form multiple traumas.

Results are not that clear when it comes to assessing the possibility of using Perfadex ${ }^{\circledR}$ for functional assessment, not using donor autologous blood, as it is currently done. Based on our experience, we have established that $\mathrm{pO}_{2}$ determination dissolved in Perfadex is higher than the blood one, on equal conditions (temperature and solution volume). We believe the absence of red blood cells in the Perfadex ${ }^{\circledR}$ solution to be the cause that is to say a lack of oxygen transport by red blood cells and the consequent increase in the measurement of the dissolved molecule concentration. This increase is in fact, progressive as the concentration of Perfadex increases and blood concentration decreases. Given that $\mathrm{pO}_{2}$ measurement related to per fused Perfadex volume presents a behavior in the shape of a polynomial, it would be possible to obtain an equation that establishes the optimum preservation volume to establish $\mathrm{pO}_{2}$ determination. However, two problems arise. The first one being that it would be a very complex equation and not too practical to be used in a routine way. The second one being that the purest in Perfadex lung circulation is, the higher the $\mathrm{pO}_{2}$ will be. Many times it beats 720 $\mathrm{mmHg}$, which is the upper limit for this determination which measures the Gem Premier 3000 therefore we do not know actual measures from that figure onwards. What is more, we have not obtained a linkage between $\mathrm{pO}_{2}$ in blood figure and $\mathrm{pO}_{2}$ in Perfadex, in order to determine the exact $\mathrm{pO}_{2}$ in Perfadex figure to start considering lungs as valid for transplant.

Therefore, we consider that the methodology clinically used for lung function assessment with outpatient non beating heart donors is valid. We also conclude that blood from the same donor or compatible blood type should be used. Finally, we believe that our findings justify exsanguinated donor assessment.

\section{Limitations of This Study}

The aim of this research is to establish the scientific basis that supports gas measurement in the pulmonary artery of non heart beating donors, after death, as it is done in type II non heart beating lung donors in Spain. Since the main goal was not assessing the protocol as a whole, but graft functional measurement, the procedure is not performed as it normally is in the clinic. Therefore, the mean period of time between cardiac arrest death and lung graft functional measurement could exceed 180 minutes. In the current study, time was reduced due to logistical arrangements. On the other hand, the fact that no organ implant has been performed in another animal, for subsequent assessment, limits the conclusions. Nevertheless, it also provides an opportunity to broaden our study, with the goal of not only reproducing the current procedure more accurately, but also of peripheral blood gas assessment of organs after implant. Assessment on implanted lungs after the animal death in order to know histopathological changes taking place will take place, as well as TNF- $\alpha$, IFN- $\gamma$, IL-1, IL-8, IL-10, IL-12 and IL-18 determinations. These being predicting factors of primary graft dysfunction [17].

\section{Acknowledgements}

This Project was subsidized by Fundacion Mutua Madrilena. 
Citation: Meneses JC, Gámez P, Mariscal A, Enguita AB, Ávila R, et al. (2013) Pulmonary Function Assessment Method with Type II Non-heart Beating Donors in Spain is Valid. J Transplant Technol Res 3: 124. doi:10.4172/2161-0991.1000124

\section{References}

1. Hamilton DN, Reid WA (1984) Yu. Yu. Voronoy and the first human kidney allograft. Surg Gynecol Obstet 159: 289-294.

2. Hardy J, Watts R Webb, Martin R Dalton (1963) Lung Homotrasplantation in man. JAMA 186: 2.

3. Hammer MD, Crippen D (2006) Brain death and withdrawal of support. Surg Clin North Am 86: 1541-1551.

4. Death rate trends for RTAs and CVAs. WHO European Health for All databases - http://www.euro.who.int/hfadb

5. Pomfret EA, Sung RS, Allan J, Kinkhabwala M, Melancon JK, et al. (2008) Solving the organ shortage crisis: the 7th annual American Society of Transplant Surgeons' State-of-the-Art Winter Symposium. Am J Transplant 8: 745-752.

6. Moradiellos Díez FJ, Varela de Ugarte A (2010) [Ex-vivo perfusion: assessment recovery and optimisation of human lungs for transplant]. Arch Bronconeumo 46: 213-214.

7. Spielman B, McCarthy CS (1995) Beyond Pittsburgh: protocols for controlled non-heart-beating cadaver organ recovery. Kennedy Inst Ethics J 5: 323-333.

8. Steen S, Sjöberg T, Pierre L, Liao Q, Eriksson L, et al. (2001) Transplantation of lungs from a non-heart-beating donor. Lancet 357: 825-829.

9. Steen S, Ingemansson R, Budrikis A, Bolys R, Roscher R, et al. (1997) Successful transplantation of lungs topically cooled in the non-heart-beating donor for 6 hours. Ann Thorac Surg 63: 345-351.
10. Gámez P, Córdoba M, Ussetti P, Carreño MC, Alfageme F, et al. (2005) Lung transplantation from out-of-hospital non-heart-beating lung donors. one-year experience and results. J Heart Lung Transplant 24: 1098-1102.

11. Ga'mez P (1995) Desarrollo de un programa de donacio'n pulmonar en asistolia con "preservacio' $n$ en bitermia» y resultados tras un ano de experiencia cli'nica. Arch Bronconeumol. 2012. Kootstra G, Daemen JHC, Oomen APA Categories of nonheartbeating Kootstra G, Daemen JH, Oomen AP Categories of non-heart-beating donors. Transplant Proc 27: 2893-2894.

12. Avlonitis VS, Fisher AJ, Kirby JA, Dark JH (2003) Pulmonary transplantation: the role of brain death in donor lung injury. Transplantation 75: 1928-1933.

13. Dark JH (2008) Lung transplantation from the non-heart beating donor Transplantation 86: 200-201.

14. "Donante marginal, en asistolia, donante lobar y valoracio'n pulmonar ex vivo". (60 minutes). Jornadas de Enfermeri'a en Trasplante. Hospital Fundacio'n Jimenez Di'az. Noviembre de 2006.

15. Egan TM, Lambert CJ Jr, Reddick R, Ulicny KS Jr, Keagy BA, et al. (1991) A strategy to increase the donor pool: use of cadaver lungs for transplantation. Ann Thorac Surg 52: 1113-1120.

16. Van Raemdonck DE, Rega FR, Neyrinck AP, Jannis N, Verleden GM, et al (2004) Non-heart-beating donors. Semin Thorac Cardiovasc Surg 16: 309-321.

17. Perrot Marc DE, Yasuo Sekine, Stefan Fischer, K. Waddell Thomas, Karen Mcrae, Mingyao Liu, A. Wigle Dennis, and Shaf Keshavjee (2002) "Interleukin-8 Release during Early Reperfusion Predicts Graft Function in Human Lung Transplantation". American Journal of Respiratory and Critical Care Medicine 165: $211-215$ 